\title{
Fetal leucocyte count in rhesus disease
}

\author{
N P Davies, A G S Buggins, R J M Snijders, P N Noble, D M Layton, K H Nicolaides
}

\begin{abstract}
The effect of fetal anaemia on the total and differential leucocyte counts was studied by examining blood samples obtained by cordocentesis from 177 previously untransfused rhesus affected fetuses at 17-36 weeks' gestation. The mean fetal total leucocyte, lymphocyte, and monocyte counts were significantly lower than the corresponding values in normal controls and there were significant associations between the decrease in these cells and the degree of fetal anaemia. Possible mechanisms for leucopenia include (i) stimulation of erythroid progenitor production at the expense of production of myeloid progenitors, (ii) nonspecific haemophagocytosis, or (iii) general suppression of haemopoiesis. Further understanding of the underlying mechanism and the implications of leucopenia as well as the previously reported thrombocytopenia and anaemia may provide a basis for improved antenatal and/or postnatal treatment.
\end{abstract}

In red cell isoimmunised pregnancies the life antibody coated red cells are destroyed in the fetal reticuloendothelial system. In mildmoderate anaemia there is associated reticulocytosis suggesting a compensatory increase in intramedullary erythropoiesis. ${ }^{1}$ With severe anaemia there is recruitment of extramedullary

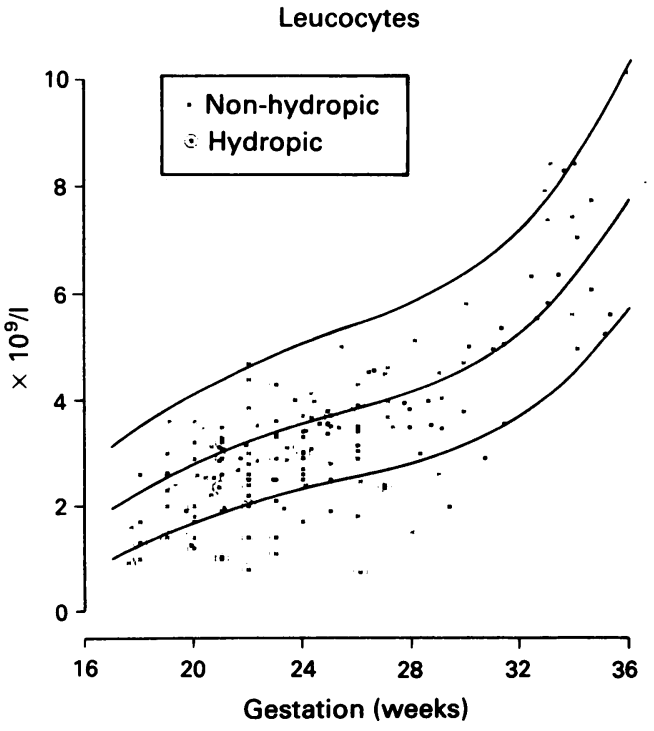
span of fetal erythrocytes is reduced because

erythropoietic sites resulting in macrocytosis and erythroblastaemia. ${ }^{12}$ In mild-moderate anaemia there is associated thrombocytosis and in severe anaemia there is thrombocytopenia. ${ }^{3}$

The aim of the present study was to examine the effect of anaemia due to rhesus isoimmunisation on the total and differential leucocyte counts.

Patients and methods

The total and differential fetal leucocyte counts were determined in a cross sectional study of 177 previously untransfused fetuses from rhesus isoimmunised pregnancies at 17-36 weeks' gestation.

Gestation was determined from the menstrual history or an ultrasound scan performed in early pregnancy. In 32 cases ultrasound evidence of fetal hydrops (skin oedema, ascites, pleural or pericardial effusions) was found. Umbilical cord blood samples were obtained by cordocentesis, which was performed without maternal sedation or fetal paralysis. ${ }^{4}$

Fetal blood $(180 \mu \mathrm{l})$ was collected into $20 \mu \mathrm{l}$ of isotonic edetic acid solution $(0.5 \mathrm{mmol} / 1$ in 0.15 $\mathrm{mmol} / \mathrm{l}$ of sodium chloride). The full blood count was determined on a Coulter Stacker Automated Cytometer (Coulter Electronics). Blood films were stained with May-GrünwaldGiemsa on an automatic processing machine and the nucleated red blood cell (NRBC) count

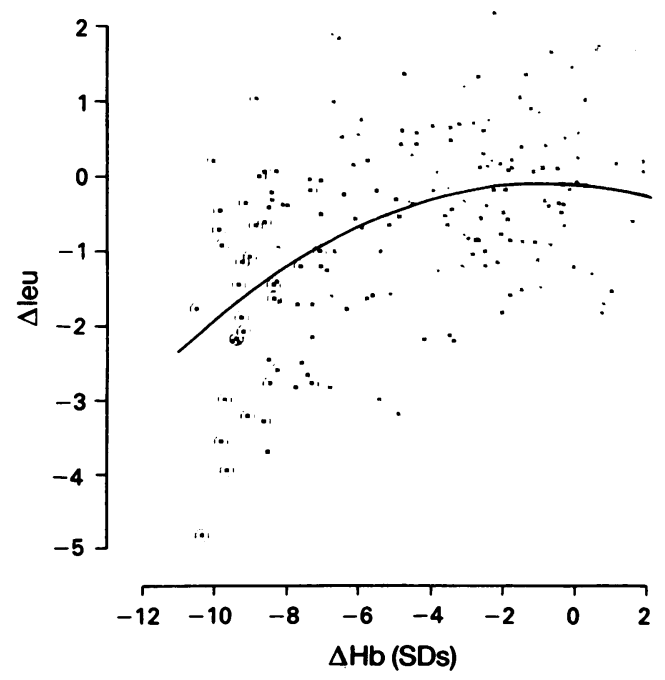

Figure 1 Total fetal blood leucocyte count in 145 non-hydropic and 32 hydropic fetuses from red cell isoimmunised pregnancies plotted on the reference range (mean, 5th, and 95 th centiles) for gestation. There is a significant association between the degree of fetalleucopenia ( $\Delta$ leu $)$ and anaemia $(\Delta H b) ; \Delta$ values represent differences from the appropriate normal meanforgestation in $S D$.
King's College School of Medicine and Dentistry, London, Harris Birthright Research Centre for Fetal Medi R J M Snijders $P$ N Noble K $\mathbf{H}$ Nicolaides Department of Haematological Medicine

A G S Buggins D M Layton

Correspondence to: Harris Birthright Research Centre Department of Obstetrics and Gynaecology,

King's College Schoo of Medicine and Dentistry, Denmark Hill, London SE5 8RX.

Accepted 13 December 1991 
per 100 leucocytes was determined. The corrected leucocyte count was calculated (leucocyte count $=$ uncorrected leucocyte count $\times 100 / N R B C$ count +100 ). To determine the differential count, 100 leucocytes were examined and classified. Kleihauer testing confirmed that all samples were fetal. Furthermore, in all cases used for this study the Coombs' test was positive.

In normal pregnancy the fetal haemoglobin concentration, platelet, and total and differential leucocyte counts change with gestation. ${ }^{356}$ The values obtained from the rhesus isoimmunised pregnancies were expressed as the number of standard deviations (SDs) by which the individual values differed from the normal mean for gestation ( $\Delta$ value). Two tailed
Student's $t$ test was applied to determine if there were significant differences between the findings in rhesus affected pregnancies and normals. Regression analysis was applied to determine the significance of any associations between $\Delta$ values for the individual parameters.

\section{Results}

In the rhesus affected pregnancies the mean fetal total leucocyte, lymphocyte, and monocyte counts were significantly lower than the corresponding values in normal controls. ${ }^{6}$ This is shown in figs 1-3; mean (SEM) difference= $-0.637(0.09)$ SDs, $t=-6.81, \mathrm{p}<0.0001$; mean difference $=-0.687 \quad(0.08) \quad$ SDs, $t=-8.3$, $\mathrm{p}<0.0001 ;$ and mean difference $=-0.536(0.08)$ SDs, $t=-6.77, p<0.0001$ respectively. There
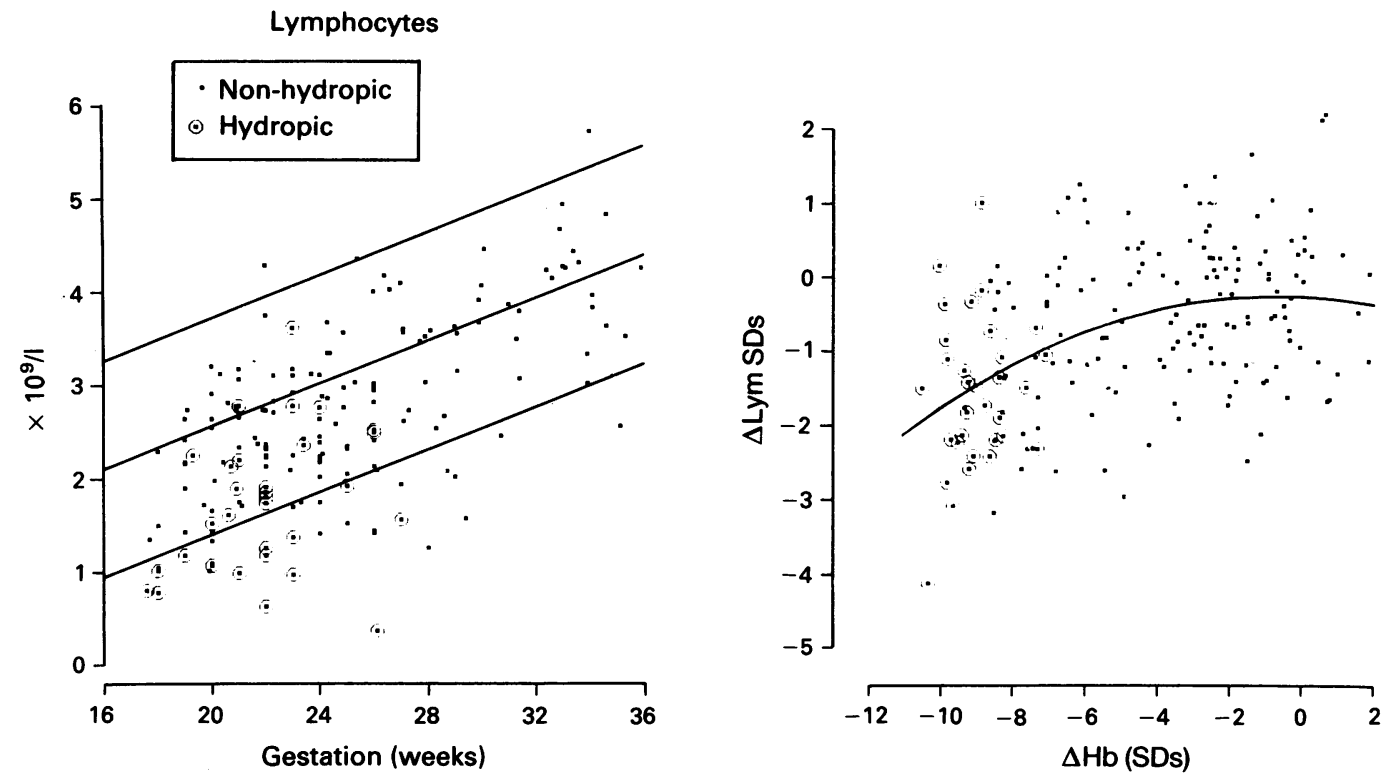

Figure 2 Fetal bloodlymphocyte count in 145 non-hydropic and 32 hydropic fetuses from red cell isoimmunised pregnancies plotted on the reference range (mean, 5th, and 95 th centiles) for gestation. There is a significant association between the degree of fetallymphocytopenia $(\Delta L y m)$ and anaemia $(\Delta H b) ; \Delta$ valuesrepresent differences from the appropriate normal mean for gestation in SDs.
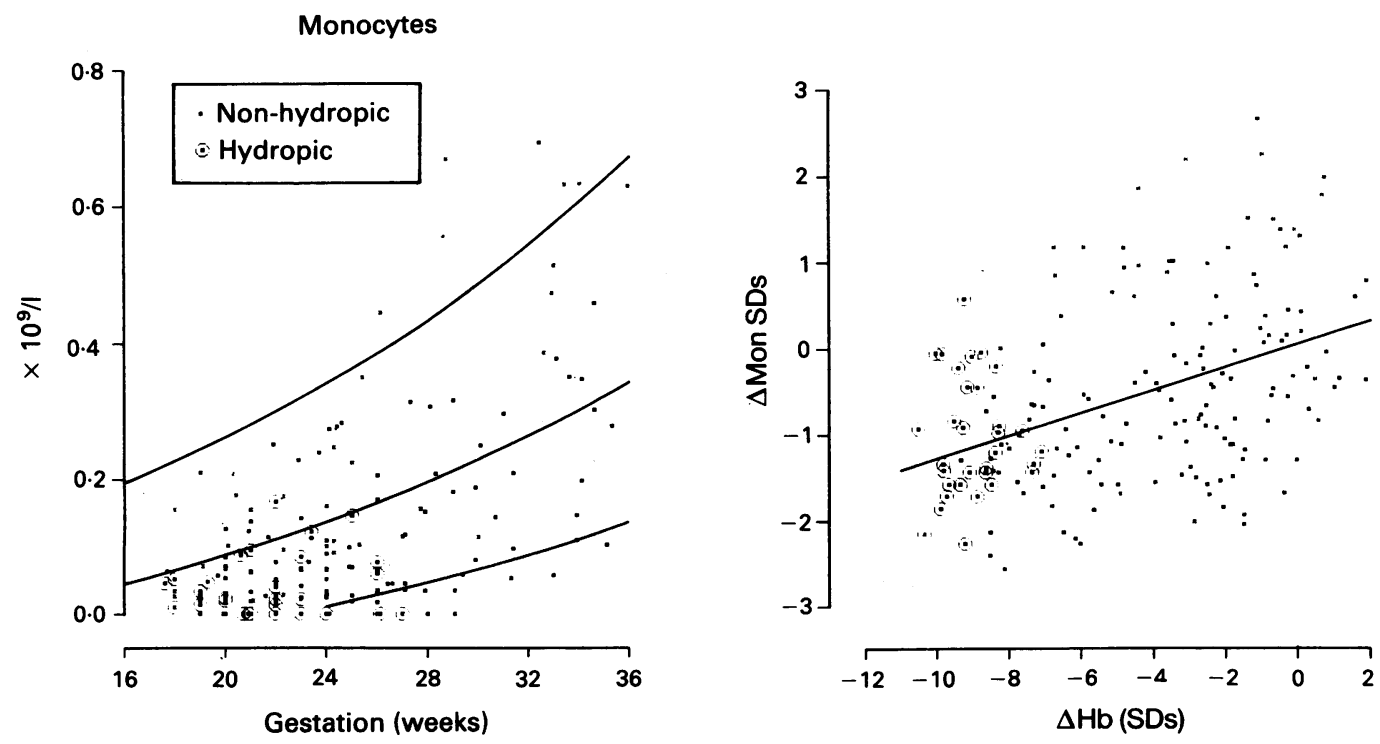

Figure 3 Fetal blood monocyte count in 145 non-hydropic and 32 hydropic fetuses from red cell isoimmunised pregnancies plotted on the reference range (mean, 5th, and 95th centiles) for gestation. There is a significant association between the degree of fetal monocytopenia $(\Delta M o n)$ and anaemia $(\Delta H b) ; \Delta$ values represent differences from the appropriate normal mean for gestation in $S D$ s. 
were no significant differences in mean neutrophil (mean difference $=0 \cdot 112(0 \cdot 09)$ SDs, $t=1 \cdot 19)$ or eosinophil counts (mean difference $=$ $\left.0.025(0.02) \times 10^{9} / 1, t=1.68\right)$.

There was a significant association between $\Delta$ total leucocyte count and $\Delta$ haemoglobin concentration which was best described by a quadratic equation (fig $1 ; \mathrm{r}=0.470, \mathrm{p}<0.0001$ ). Multiple regression analysis showed that hydrops did not have a significant independent contribution to this association ( $F$ to remove hydrops $=2.93, p=0.09$ ). Similarly, there was a significant quadratic association between $\Delta$ lymphocyte count and $\Delta$ haemoglobin concentration (fig 2; $r=0.439, p<0.05$ ). There was a significant linear association between $\Delta$ monocyte count and $\Delta$ haemoglobin concentration (fig 3; $\mathrm{r}=0.413, \mathrm{p}<0.0001$ ).

\section{Discussion}

In rhesus isoimmunisation fetal haemolysis is associated with leucopenia. Lymphocyte and monocyte counts decreased in proportion to the degree of fetal anaemia, although neutrophil numbers appeared to be unaffected. Koenig and Christensen, using blood samples obtained postnatally from infants of rhesus affected pregnancies, also reported an association between leucopenia and severe aneamia. ${ }^{7}$ However, their findings suggested that the infants were neutropenic. A possible explanation for this apparent discrepancy is that in intrauterine life, especially before 32 weeks' gestation, neutrophil counts are normally quite low (1-3 per 100 white cells) making it difficult to demonstrate a significant reduction. ${ }^{6}$

Haemopoiesis defines the production of functionally distinct mature blood cells from a common pluripotent progenitor. It is possible that in severe anaemia due to rhesus isoimmunisation the observed leucopenia, as well as the previously described thrombocytopenia, ${ }^{3}$ may reflect the coordinated differentiation of erythroid progenitors at the expense of myeloid and megakaryocytic maturation. Although such 'channelling' of haemopoietic reserve is not commonly observed in postnatal haemolysis, Koenig and Christensen have reported that in some neonates with severe red cell isoimmunisation there is an increase in the number of erythroid progenitors accompanied by a reduction in numbers of granulocyte-macrophage progenitors. ${ }^{7}$ Furthermore, addition of erythropoietin to cultures of human fetal progenitors reduces the number of granulocyte-macrophage colonies formed in response to granulocytemacrophage colony stimulating factor. ${ }^{8}$

A further possible explanation for leucopenia and thrombocytopenia in red cell isoimmunisation is non-specific haemophagocytosis due to activation of the reticuloendothelial system.9
This process has been observed in autoimmune haemolytic anaemia. ${ }^{10}$ Although the phenomenon was thought to be rare, Suster $e t$ al have recently examined 230 consecutive adult necropsies and found evidence of moderate to severe haemophagocytosis in the bone marrow of 102 cases. $^{11}$

In those cases where leucopenia and thrombocytopenia are associated with absence of an erythroid response, marrow suppression due to tissue hypoxia and lactic acidosis may be important. ${ }^{12} 13$ Additionally, as in postnatal life, severe haemolysis and consequent increased erythropoietic activity could result in relative deficiency of haematinics such as folate. ${ }^{14}$

In summary, this study demosntrates that in rhesus affected fetuses severe anaemia is not only accompanied by thrombocytopenia but also by leucopenia. Possible mechanisms causing the reduced numbers of white cells and platelets include (i) stimulation of erythroid progenitor production at the expense of production of myeloid and megakaryocyte progenitors, (ii) non-specific haemophagocytosis, or (iii) general suppression of haemopoiesis. Further studies on the underlying mechanism and the implications of presence of leucopenia as well as thrombocytopenia and anaemia may provide a basis for improved antenatal and/or postnatal treatment.

1 Nicolaides $\mathrm{KH}$, Thilaganathan B, Rodeck $\mathrm{CH}$, Mibashan RS. Erythroblastosis and reticulocytosis in anemic fetuses. Am f Obstet Gynecol 1988;159:1063-5.

2 Nicolaides KH, Snijders RJM, Thorpe-Beeston G, Van den Hof M, Gosden C, Bellingham AJ. Mean red cell volume in normal, small and anemic fetuses. Fetal Therapy 1989;4: $1-13$.

3 Van den Hof MC, Nicolaides KH. Platelet count in normal, small, and anemic fetuses. Am $\mathcal{f}$ Obstet Gynecol 1990;162: 735-9.

4 Nicolaides KH, Soothill PW, Rodeck CH, Campbell S. Ultrasound guided sampling of umbilical and placental blood to assess fetal wellbeing. Lancet 1986;i:1065-7.

5 Nicolaides KH, Soothill PW, Clewell WH, Rodeck CH, Mibashan R, Campbell S. Fetal hemoglobin measurement in the assessment of red cell isoimmunization. Lancet 1988; i:1073-5.

6 Davies NP, Buggins AGS, Snijders RJM, Jenkins E, Layton DM, Nicolaides KH. Blood leucocyte count in the human fetus. Arch Dis Child 1992;67:399-403.

7 Koenig JM, Christensen RD. Neutropenia and thrombocytopenia in infants with $\mathrm{Rh}$ hemolytic disease. $\mathcal{f}$ Pediatr 1989;114:625-31.

8 Migliaccio AR, Migliaccio G. Human embryonic hemopoiesis: control mechanisms underlying progenitor differentiation in vitro. Dev Biol 1988;125:127-34.

9 Farquhar JW, MacGregor AR, Richmond J. Familial haemophagocytic reticulosis. $B M \mathcal{F}$ 1958;ii: $1561-4$.

10 Rappaport H, Crosby WH. Autoimmune hemolytic anemia. II. Morphologic observations and clinicopathologic correlations. Am J Pathol 1957;33:429-49.

11 Suster S, Hilsenbeck S, Rywlin AM. Reactive histiocytic hyperplasia with hemophagocytosis in hematopoietic organs: a reevalutaion of the benign hemophagocytic proliferations. Hum Pathol 1988;19:705-12.

12 Soothill PW, Nicolaides KH, Rodeck CH. The effect of anaemia on fetal acid-base status. Br $\mathcal{F}$ Obstet Gynaecol 1987;94:880-3.

13 Nicolaides $\mathrm{KH}$. Studies on fetal physiology and pathophysiology in rhesus disease. Semin Perinatal 1989;13: 328-37.

14 Lopez R, Shimizu N, Cooperman JM. Recurrent folic acid deficiency in sickle cell disease. Am $\mathcal{F}$ Dis Child 1973;125:
$544-8$. 